\title{
The South Korean Twin Registry: An Update
}

\author{
Yoon-Mi Hur, ${ }^{1}$ Hoe-Uk Jeong, ${ }^{2}$ Kee Wha Chung, ${ }^{3}$ Joong Sik Shin, ${ }^{4}$ and Tae-Bok Song ${ }^{5}$ \\ ${ }^{1}$ Industry-Academics Cooperation Foundation, Mokpo National University, Jeonnam, South Korea \\ ${ }^{2}$ Department of Education, Mokpo National University, Jeonnam, South Korea \\ ${ }^{3}$ Department of Biology, Kongju National University, Kongju, South Korea \\ ${ }^{4}$ Department of Obstetrics \& Gynecology, CHA University School of Medicine, Seoul, South Korea \\ ${ }^{5}$ Department of Obstetrics \& Gynecology, Jeonnam National University Hospital, Kwangju, South Korea
}

The South Korean Twin Registry (SKTR) is an ongoing nation-wide volunteer registry of South Korean twins and their families, which was established in the year 2001 to understand genetic and environmental etiologies of psychological and physical traits among South Koreans. Recently, the SKTR sampling has been extended in two important ways. First, we began to recruit twins from lower socio-economic families to study interaction effects of gene by environmental context. Second, as a parallel study of the SKTR, the Nigerian Twin and Sibling Registry was developed to understand the origin of the population group differences/similarities in psychological traits between South Koreans and Nigerians. This article summarizes the main findings (based on the SKTR sample to date), recruitment procedures, zygosity assessment, measures, and future plans for the SKTR.

Keywords: twin, genetics, South Korea, psychological traits, physical traits, mental health

\section{A Review of the Past Findings and Current Major Research Issues}

The South Korean Twin Registry (SKTR) is an ongoing nation-wide volunteer registry of South Korean twins and their families. The general goal of the SKTR is to understand genetic and environmental etiologies of psychological and physical traits among South Koreans. Since its inception (Hur, 2002; Hur et al., 2006), twin studies based on the SKTR samples have demonstrated that genetics play a significant role in individual differences in many physical and psychological traits among South Koreans, especially from childhood to young adulthood (Table 1). For physical traits, body mass index (BMI), and cold hands symptoms in adolescence and young adulthood showed very high heritability (about 60-90\%) with little shared environmental influences (Hur, 2007a; Hur et al., 2008, 2012) although during childhood these traits were significantly influenced by shared environmental factors (Hur \& Shin, 2008). Substantial intrauterine environmental influence was also observed in birth weight (Hur et al., 2005). Genetic influences on childhood temperament and adolescent personality traits fell between $30 \%$ and $60 \%$, of which non-additive genetic effects were important (Hur, 2006, 2007b, 2009a; Hur \& Rushton, 2007; Hur et al., 2011). For personality traits, shared environmental influences were generally negligible during childhood and adolescence as well as in young adulthood. Environmental factors important for personal- ity and temperament were primarily those resulted from individual-specific experiences (Hur, 2006, 2007b, 2009a; Hur \& Rushton, 2007; Hur et al., 2011). The estimates of genetic influences on many psychiatric symptoms were similar to those found in personality traits (Hur, 2008, 2009b; Hur \& Jeong, 2008; Hur et al., 2012). However, shared environmental influences were notable in conduct problems (Ha et al., 2010), depressive symptoms in males (Hur, 2008), and obsessive-compulsive symptoms in females (Hur \& Jeong, 2008). As with personality traits, many psychiatric symptoms demonstrated that individual-specific environmental influences were important sources of variation. Overall, these findings based on the SKTR samples were consistent with the results from Western twin samples, suggesting that the proportions of genetic and environmental influences on psychological and physical traits found in Western countries may be generalized to South Koreans.

Our current major research focus of the SKTR samples includes detection of $\mathrm{G} \times$ E interactions for the mean level as well as for the variations of psychological and physical phenotypes. To examine the process of $\mathrm{G} \times \mathrm{E}$ interactions, we

RECEIVED 15 September 2012; ACCEPTED 14 October 2012. First published online 30 November 2012.

ADDRESS FOR CORRESPONDENCE: Yoon-Mi Hur, Mokpo National University, Jeonnam, South Korea. E-mail: ymhur@mokpo.ac.kr 


\begin{tabular}{|c|c|c|c|c|c|}
\hline \multicolumn{6}{|c|}{$\begin{array}{l}\text { Genetic and Environmental Influences (\%) on Various Traits Estimated From Sub-Samples of the South Korean Twin } \\
\text { Registry }^{a}\end{array}$} \\
\hline Measure & Age & $A+D$ & C & $\mathrm{E}$ & Reference \\
\hline \multicolumn{2}{|l|}{ Birth weight (males) } & 15 & 48 & 36 & \multirow[t]{2}{*}{ Hur et al. (2005) } \\
\hline \multicolumn{2}{|l|}{ Birth weight (females) } & 16 & 52 & 31 & \\
\hline BMI & $1.9-8.7$ years & $55(43-68)$ & $35(22-47)$ & $10(8-13)$ & Hur \& Shin (2008) \\
\hline Cold hands symptoms & $12-24$ years & $64(55-72)$ & - & $36(28-45)$ & Hur et al. (2012) \\
\hline Hostility & $13-23$ years & $34(30-36)$ & - & $66(64-70)$ & Hur (2006) \\
\hline Eysenckian scales ${ }^{b}$ & $13-23$ years & 42 & - & 58 & Hur (2007b) \\
\hline $\mathrm{EAS}^{\mathrm{c}}$ & $2-9$ years & 39 & - & 61 & Hur (2009) \\
\hline Depression symptoms (females) & $13-23$ years & $41(0-52)$ & $0(0-36)$ & $59(48-72)$ & Hur (2008) \\
\hline Obsessive-compulsive symptoms (males) & $13-23$ years & $53(45-59)$ & - & $47(41-55)$ & Hur \& Jeong (2008) \\
\hline Obsessive-compulsive symptoms (females) & $13-23$ years & $41(33-48)$ & - & $59(52-67)$ & Hur \& Jeong (2008) \\
\hline Conduct problems & 4-13 years & - & 39 & 61 & Ha et al. (2010) \\
\hline Hallucination symptoms & $12-19$ years & $33(23-42)$ & - & $67(60-77)$ & Hur et al. (in press) \\
\hline
\end{tabular}

make efforts to identify specific genetic, and environmental protective and risk factors for psychological and physical traits. We also investigate developmental differences in genetic and environmental influences on phenotypes and endophenotypes, using age as a continuous moderator. The large age span of twin participants in the SKTR enables us to pursue this research question. In line with these research interests, we recently extended the SKTR sampling in two important ways. First, as explained below, we began to recruit twins from lower socio-economic families, which will facilitate studies of interactions between genetics and social classes. Second, as a parallel twin study of the SKTR, we started to develop an age-matched sample of Nigerian twins and siblings (Hur et al., 2013 in this issue). The combined data sets of Nigerian and South Korean twins will provide a unique opportunity to investigate population group differences/similarities in psychological traits between South Korean and Nigerian children and adolescents.

\section{Registry Membership}

Twins in the SKTR have been recruited from a variety of sources, including large maternity hospitals, twin mothers' clubs, media advertisement, and kindergartens and schools throughout South Korea (Hur et al., 2006). More recently, to reach twins from lower socio-economic families who are typically under-represented in volunteer research projects, we began to call and send letters to the community child centers and youth counseling centers supported by the government in all provinces in South Korea. As these centers support children and adolescents from poor families and those with problem behaviors, a successful recruitment of
TABLE 2

Number a of Twins Who Have Been Registered With the SKTR By Age Group and the Sex-Ratio of Each Age Group

\begin{tabular}{lrl}
\hline Age group & \multicolumn{1}{c}{$N$} & Sex ratio (M:F) \\
\hline Children (age $<8$ years) & 5,210 & $45: 55$ \\
Adolescents (7 years $<$ age $<19$ years) & 13,230 & $48: 52$ \\
Young adults (age $>18$ years) & 3,048 & $47: 53$ \\
\hline Total & 21,488 & \\
\hline
\end{tabular}

Note: ${ }^{a}$ Individual twins.

these children and adolescents is likely to make the participants of the SKTR well representative of a large number of low-income as well as middle- to upper-class families in South Korea.

Due to a high mobility rate among residents in large cities in South Korea, however, we have lost the contact information of twins for the past years. To replenish the registry membership, we continue to recruit new volunteers as well as to trace contact information of the twins who moved. Table 2 presents the number of individual twins who have been at least once registered with the SKTR.

\section{Zygosity Assignment}

Opposite-sex twins in the SKTR are automatically assigned to dizygotic twins. Zygosity assignment for the same-sex twins is initially based on the questionnaire method and in some cases by chorionicity determined by the examination of placentas in the pathology lab after delivery. However, the questionnaire method is currently supplemented with analysis of 16 micro-satellite DNA markers. 
TABLE 3

Description of Selected Measures Used in the South Korean Twin Registry

\begin{tabular}{|c|c|c|}
\hline Domain & Description & Source \\
\hline \multirow[t]{2}{*}{ Cognitive abilities } & Non-verbal general ability & $\begin{array}{l}\text { Standard Progressive Matrices-Plus version (Raven, } \\
\text { 2008) }\end{array}$ \\
\hline & Verbal general ability & Mill Hill Vocabulary Scale (Raven, 2008) \\
\hline \multirow[t]{3}{*}{ Personality } & Adolescent personality & Eysenck Personality Scale (Eysenck \& Eysenck, 1991) \\
\hline & Childhood temperament & EAS (Buss \& Plomin, 1984) \\
\hline & & $\begin{array}{l}\text { Economic Behaviors } \\
\text { Strenaths and Difficulties Questionnaire (Goodman }\end{array}$ \\
\hline \multirow{11}{*}{ Mental health } & Behavioral problems & $\begin{array}{l}\text { Strengths and Difficulties Questionnaire (Goodman, } \\
\text { 1997) }\end{array}$ \\
\hline & Anger & State-Trait Anger Scale (Brunner \& Spielberger, 2009 \\
\hline & Anxiety & State-Trait Anxiety Scale (Spielberger, 1983) \\
\hline & Hostility & Koskenvuo et al. (1988). \\
\hline & Morningness-eveningness & Composite Scale (Smith et al., 1989). \\
\hline & Hallucination & $\begin{array}{l}\text { Launey-Slade Hallucination Scale -Revised (Launay \& } \\
\text { Slade, 1981). }\end{array}$ \\
\hline & Clinical symptoms & Personality Assessment Inventory (Morey, 1991) \\
\hline & Depression & CES-D (Cho \& Kim 1998) \\
\hline & Obsessive-compulsive symptoms & $\begin{array}{l}\text { Maudsley Obsessive-Compulsive Inventory (Hodgson } \\
\text { \& Rachman, 1977). }\end{array}$ \\
\hline & Substance use & \\
\hline & Perception of social support & \\
\hline \multirow[t]{2}{*}{ Family environment } & Physical environment & Family Asset questionnaire \\
\hline & Psychological environment & FACES III (Olson et al., 1985) \\
\hline \multirow[t]{6}{*}{ Physical development } & Puberty (self-report) & \\
\hline & Birth weight (parental report) & \\
\hline & Height, weight (self-report; parental report) & \\
\hline & Chorionicity (lab examination) & \\
\hline & Cold hands symptom (self-report) & \\
\hline & General health (self-report, parental report) & \\
\hline Demographic information & $\begin{array}{l}\text { Parents' education, occupation, religion (self-report, } \\
\text { parental report) }\end{array}$ & \\
\hline
\end{tabular}

\section{Measures}

Studies using the SKTR samples encompass a broad range of psychological and physical domains. The measures for the SKTR samples have been chosen for their high psychometric properties and for their broad acceptance in the field. These practices allow cross-national comparison studies. Table 3 provides an overview of selected measures used in the SKTR.

\section{Conclusions and Future Plans}

This article is not an exhaustive description of all the studies of the SKTR. Development of the SKTR is an ongoing process. Plans are still underway to conduct extensive genotyping in order to examine polymorphisms associated with psychological and physical traits among South Koreans. Efforts are also being made for epigenetic analyses and co-twin-control studies using a subset of the SKTR sample.

\section{Acknowledgments}

The SKTR has been supported by the National Research Foundation grants in Korea and Pioneer Fund, USA. The authors would like to thank the twins and their families and many research assistants who participated in the SKTR.

\section{References}

Brunner, T. M., \& Spielberger, C. D. (2009). State-traitanger expression inventory-2 child and adolescent. Professional manual. Lutz: Psychological Assessment Resources.

Buss, A. H., \& Plomin, R. (1984). Temperament: Early developing personality traits. Hillsdale, NJ: Erlbaum.

Cho, M. J., \& Kim, K. H. (1998). Use of the center for epidemiologic studies-depression scale in Korea. Journal of Nervous and Mental Disease, 186, 304-310.

Eysenck, H. J., \& Eysenck, S. B. G. (1991). Manual of the eysenck personality scales. London: Hodder \& Stoughton.

Goodman, R. (1997). The strengths and difficulties questionnaire: A research note. Journal of Child Psychology and Psychiatry, 38, 581-586.

Ha, N., Jin, M. J., Koo, S., Jo, O., Kim, B., Kim, K., ... Hur, Y.-M. (2010). Genetic and environmental covariations between emotional problems and conduct problems in South Korean twin children. Abstracts for the 13th International Congress on Twin Studies. Twin Research and Human Genetics, 13, 261.

Hodgson, R. J., \& Rachman, S. (1977). Obsessional-compulsive complaints. Behavior Research and Therapy, 15, 389-395.

Hur, Y.-M. (2002). Seoul Twin Family Study: Design, sampling, assessments, and future directions. Twin Research, 5, 389393.

Hur, Y.-M. (2006). Nonadditive genetic effects on hostility in South Korean adolescent and young adult twins. Twin Research and Human Genetics, 9, 637-654. 
Hur, Y.-M. (2007a). Sex difference in heritability of BMI in South Korean adolescent twins. Obesity, 15, 29082911.

Hur, Y.-M. (2007b). Evidence for nonadditive genetic effects on Eysenck Personality Scales in South Korean twins. Twin Research and Human Genetics, 10, 373-378.

Hur, Y.-M. (2007c). Stability of genetic influence on morningness-eveningness: A cross-sectional examination of South Korean twins from preadolescence to young adulthood. Journal of Sleep Research, 16, 17-23.

Hur, Y.-M. (2008). Sex difference in genetic and environmental contributions to depression symptoms in South Korean adolescent and young adult twins. Twin Research and $\mathrm{Hu}$ man Genetics, 11, 306-313.

Hur, Y.-M. (2009a). Genetic and environmental contributions to childhood temperament in South Korean twins. Twin Research and Human Genetics, 12, 549-554.

Hur, Y.-M. (2009b). Genetic and environmental contributions to the covariations between obsessive-compulsive symptoms, neuroticism, and extraversion. Twin Research and Human Genetics, 12, 142-149.

Hur, Y.-M., Chae, J.-H., Chung, K. W., Kim, J.-J., Jeong, H.-U., Kim, J. W., ... Kim, K. S. (2012). Feeling of cold hands and feet is a highly heritable phenotype. Twin Research and Human Genetics, 15, 166-169.

Hur, Y.-M., Cherney, S. S., \& Sham, P. C. (2012). Heritability of hallucinations in adolescent twins. Psychiatry Research. Retrieved from http://dx.doi.org/10.1016/ j.psychres.2012.04.024

Hur, Y.-M., \& Jeong, H.-U. (2008). Sex differences in genetic and environmental influences on obsessive-compulsive symptoms in South Korean adolescent and young adult twins. Twin Research and Human Genetics, 11, 314320.

Hur, Y.-M., Jeong, H.-U, Schermer, J., \& Rushton, J. P. (2011). Miserliness is heritable. Personality and Individual Differences, 51, 1052-1055.

Hur, Y.-M., Kaprio, J., Iacono, W. G., Boomsma, D. I., McGue, M., Silventoinen, K., . . . Mitchell, K. (2008). Genetic influences on the difference in variability of height, weight and body mass index between Caucasian and East Asian ado- lescent twins. International Journal of Obesity, 32, 14551467.

Hur, Y.-M., Kim, J. W., Chung, K. W., Shin, J. S., Jeong, H.-U., \& Auta, E. (2013). The Nigerian Twin and Sibling Registry. Twin Research and Human Genetics, 16, 1.

Hur, Y.-M., Luciano, M., Martin, N. G., Boomsma, D. I., Iacono, W. G., McGue, M., ... Han, J. Y. (2005). A comparison of twin birth weight data from Australia, the Netherlands, the United States, Japan, and South Korea: Are genetic and environmental variations in birth weight similar in Caucasians and East Asians? Twin Research and Human Genetics, 8, 638-648.

Hur, Y.-M., \& Rushton, J. P. (2007). Genetic and environmental contributions to prosocial behavior in 2- to 9- year-old South Korean twins. Biology Letters, 22, 664-666.

Hur, Y.-M., \& Shin, J. (2008). Effects of chorion type on genetic and environmental influences on height, weight, and body mass index in South Korean young twins. Twin Research and Human Genetics, 11, 63-69.

Hur, Y.-M., Shin, J., Jeong, H.-U., \& Han, J. Y. (2006). The South Korean Twin Registry. Twin Research and Human Genetics, 9, 838-843.

Koskenvuo, M., Kaprio, J., Rose, R. I., Kesaniemi, A., Sara, S., \& Heikkila, K. (1988). Hostility as a risk factor for mortality and ischemic heart disease in men. Psychosomatic Medicine, 50, 330-340.

Launay, G., \& Slade, P. D. (1981). The measurement of hallucinatory predisposition in male and female prisoners. Personality and Individual Differences, 2, 221-234.

Morey, L. C. (1991). Personality Assessment Inventory, professional manual. Lutz, FL: Personality Assessment Resources.

Olson, D. H., Portner, J., \& Lavee, Y. (1985). FACES III. St. Paul, MN: Family Social Science, University of Minnesota.

Raven, J. (2008). Standard progressive matrices-plus version and Mill Hill Vocabulary Scale. Manual. London: Pearson.

Smith, C. S., Reilly, C., \& Midkiff, K. (1989). Evaluation of three circadian rhythm questionnaires with suggestions for an improved measure of morningness. Journal of Applied Psychology, 74, 728-738.

Spielberger, C. D. (1983). State-Trait Anxiety Inventory (Form Y). Menlo Park: Mind Garden. 